คำ

columns

\section{Roles and Responsibilities of the Consultant in General Adult Psychiatry}

Council Report CR140, August 2006, Royal College of Psychiatrists, f7.50, $60 \mathrm{pp}$

This report is a revised and updated version of Roles and Responsibilities of the Consultant in General and Community Psychiatry (Council Report CR94; Royal College of Psychiatrists, 2001). The document provides a positive vision of the role of the specialist in general adult psychiatry. It reaffirms the value and validity of the role, and its centrality in the provision of mental health services to the working age adult population. The role and responsibilities are defined in relation to the service and the multidisciplinary team, and evidence-based developments in treatment, care and services are supported.
Consultants in general adult psychiatry are specialists in the diagnosis and assessment, management and prevention of the full range of mental health disorders affecting adults of working age. Their expertise is deployed in a wide range of settings, reflecting the needs of patients. They require a detailed knowledge of mental disorders affecting the adult population, the multiple factors affecting these disorders, and the basic sciences relevant to assessment, diagnosis and treatment.

Key values and attitudes include: partnership working with patients and carers, a social care perspective, and multidisciplinary and multi-agency working. The central skills of the consultant in general adult psychiatry are defined in the report.

There are recommendations for the clarification of clinical responsibility carried by the consultant and other members of the team. Trusts should draw up guidance for clinical responsibility, taking account of national statutes, the guidance of professional bodies and local circumstances.

The report is in line with the New Ways of Working for Psychiatrists (Department of Health, 2005) and views consultants as a resource to the multidisciplinary team and the wider health and social care community. It recommends that consultants carry small personal case-loads which are compatible with locally agreed job plans, and that they are enabled to work in a consultative fashion, prioritising the needs of complex patients and those with severe disability. In addition, consultants have a responsibility to provide leadership in their clinical setting and have a crucial role in contributing to the service design. They also have an important role in advocating for individual patients or more broadly for such things as improvements in services, rights and social justice for people with mental health problems.

Included in the appendices are the reports of the working groups set up between the Faculty of General and Community Psychiatry and the other individual faculties.

DEPARTMENT OF HEALTH (2005) NewWays of Working for Psychiatrists. Department of Health.

doi: 10.1192/pb.bp.107.015735 